
\title{
25 Research Square \\ Depth dependence of climatic controls on soil microbial community activity and composition
}

Nicholas Dove ( $\square$ ndove7@gmail.com )

Oak Ridge National Laboratory https://orcid.org/0000-0003-1152-956X

\section{Morgan Barnes}

Pacific Northwest National Laboratory

Kimber Moreland

Lawrence Livermore National Laboratory

Robert Graham

University of California, Riverside

Asmeret Berhe

University of California, Merced https://orcid.org/0000-0002-6986-7943

Stephen Hart

University of California-Merced https://orcid.org/0000-0002-9023-6943

\section{Article}

Keywords: 16S rRNA, bioclimatic gradient, critical zone, extracellular enzyme activity, ITS gene, soil microbial ecology, subsoil

Posted Date: August 6th, 2021

DOI: https://doi.org/10.21203/rs.3.rs-787969/v1

License: (1) This work is licensed under a Creative Commons Attribution 4.0 International License. Read Full License

Version of Record: A version of this preprint was published at ISME Communications on December 1st, 2021. See the published version at https://doi.org/10.1038/s43705-021-00081-5. 


\section{Abstract}

Subsoil microbiomes play important roles in soil carbon and nutrient cycling, yet our understanding of the controls on microbial communities in the subsoil is limited. Here, we investigate the direct (mean annual temperature and precipitation) and indirect (soil chemistry) effects of climate on microbiome composition and activity throughout the soil profile across two elevation-bioclimatic gradients in central California, USA. We show that microbiome composition changes and activity decreases with depth. Across these sites, the direct influence of climate on microbiome composition and activity was relatively lower at depth. Furthermore, we find that certain microbial taxa change in relative abundance over large temperature and precipitation gradients only in specific soil horizons, highlighting the depth dependence of the climatic controls on microbiome composition. Our finding that the direct impacts of climate are muted at depth suggests that deep soil microbiomes may lag in their acclimation to new temperatures with a changing climate.

\section{Introduction}

Microbial community composition varies considerably throughout the soil profile ${ }^{1}$ likely due to edaphic factors that change with depth, including organic carbon (C) availability, nutrients, $\mathrm{pH}$, and texture ${ }^{2-5}$. However, most studies on subsoil microbial communities do not span large ecological gradients, preventing a complete understanding of large-scale drivers of subsoil microbial communities. Therefore, across broad ecological gradients, our understanding of the controls of subsoil microbial communities is incomplete for bacteria ${ }^{1}$ and even more limited for fungi. Climate is often considered a major driver of microbial community composition and activity at large spatial scales in the surface soil ${ }^{6-8}$. However, the relative strength of climate in predicting subsoil microbial community composition and activity is still unclear.

The direct effects of climate on microorganisms are dictated by temperature, precipitation, and aridity, and how these factors vary and covary seasonally ${ }^{9}$. Given that microorganisms and their extracellular enzymes have different temperature and moisture optima ${ }^{10-12}$, climatic adaptations are common. Indeed, various microorganisms in the surface soil, particularly within the phyla Actinobacteria and Chloroflexi, have been shown to respond positively to increased temperatures ${ }^{13}$. Climate can also affect microbial communities indirectly through its influence on soil development. For instance, climate is one of the five state factors of soil development ${ }^{14}$, affecting the availability of inorganic nutrients, soil texture, and organic matter ${ }^{9}, 15$, all of which impact microbial community dynamics. Additionally, wetter climates generally lead to decreased $\mathrm{pH}^{16}$, a major correlate of microbial community structure ${ }^{17,18}$, through base cation leaching and accumulation of iron and aluminum colloids ${ }^{19}$. Finally, climate often covaries with vegetation ${ }^{20}$, leading to differences in organic substrate abundance and chemical composition available for microbial degradation among climatic envelopes ${ }^{21,22}$. Hence, together, these direct and indirect effects lead to strong bioclimatic patterns of soil microbial community structure and activity in surficial soils.

Climatic effects on subsoil microbial communities may differ compared to their surface soil counterparts. While the surface soil interfaces directly with air temperature and precipitation, the surface soil modulates the impacts of climatic changes on the underlying subsoil. Thus, seasonal and diurnal fluctuations in temperature and moisture are muted at depth ${ }^{23,24}$. This could lead to two alternative scenarios: 1) subsoil microbial 
communities are less adapted to climate, whereby moderate temperature and moisture levels are not strong selective pressures; or 2) subsoil microbial communities are more adapted to climate, whereby reduced temperature and moisture fluctuations select for highly constrained microbial communities. Recent evidence suggests that subsoil microbial community composition may be less responsive to climatic conditions. For example, the effect of 4.5 years of experimentally increased temperature was reduced at depth. This was likely due to metabolic capabilities of subsoil microbial communities that allow for the decomposition of a variety of complex organic matter substrates that are enriched with warming ${ }^{25}$. Additionally, laboratory warming $\left(+10^{\circ} \mathrm{C}\right)$ of Tibetan soils showed that subsoil microbial communities are, in general, less responsive to altered temperatures, at least in the short-term (30 day; Bai et al. ${ }^{26}$. However, the full effect of climate may not emerge over such short timescales, because the indirect effects of climate (i.e., changes in vegetation and soil chemistry) may take decades to develop. Therefore, well-constrained, observational studies investigating the longer-term direct and indirect effects of climate on the subsoil microbial community are particularly valuable for capturing the full effect of climate.

Understanding the controls on microbial communities at depth is particularly important because they are relatively understudied ${ }^{27}$ and they play a significant role in decomposing the $\sim 1,400 \mathrm{Pg}$ of soil organic carbon (SOC) stored below $20 \mathrm{~cm}^{28}$. For instance, over half of extracellular enzyme activity in the upper meter of the soil profile occurs below $20-\mathrm{cm}^{5}$. Furthermore, when warmed, subsoil respiration can account for over $40 \%$ of the increase in $\mathrm{CO}_{2}$ emissions from the whole soil profile ${ }^{29}$. Finally, laboratory rates of $\mathrm{C}$ and $\mathrm{N}$ mineralization of added substrates were as fast in the subsoils as in surface soils in an old-growth forest, suggesting that microbial competition and demand for $\mathrm{C}$ and $\mathrm{N}$ resources does not decrease with depth ${ }^{30}$. Taken together, these results suggest that subsoil microbial communities are important mediators of deep $\mathrm{C}$ persistence. Within the context of a changing climate, climate-induced alterations to the microbial community could enhance SOC loss from the subsoil, exacerbating climate change ${ }^{31,32}$. Hence, our understanding of the climatic controls of subsoil microbial communities and how these differ from surface soils is integral in constraining long-term soil C storage predictions.

To understand the impact of climate on microbial community composition and activity throughout the soil profile, we collected soil samples from each genetic horizon (A to $C$ ) in soil pits along two elevational gradients (Figure 1A). Elevational transects are valuable bio-climatic gradients that can be used to study the long-term impact of climate on soils, particularly when other soil development state factors are held constant ${ }^{33}$. These samples were analyzed for prokaryote and fungal community composition (16S rRNA and ITS gene, respectively), potential activity (using extracellular enzyme activity assays), and soil chemistry. We hypothesized that the microbial community composition and activity would vary with direct effects of climate (mean annual air temperature [MAT] and precipitation [MAP]) across soil horizons, but the direct effect of climate would be reduced at depth, consistent with the few previous studies conducted to date (e.g., Bai et al. ${ }^{26}$, Dove et al. ${ }^{25}$ ). Additionally, we hypothesized that, deeper in the soil profile, the indirect effects of climate, namely soil chemistry, would become the dominant control of microbial community composition and activity. We also hypothesized that microbial taxa have distinct traits related to climate such that we would detect specific taxa that correlate with the direct effects of climate both throughout the soil profile and within major horizons. Given our study design, we were also able to test the hypothesis that soil Master horizon would be a stronger predictor of microbial community composition than depth increment. The overall goal of our study 
was to provide a greater understanding of microbial communities and depth and to elucidate their patterns as they relate to climate. Such knowledge should improve our ability to predict microbial decomposition and soil C stocks in a changing climate.

\section{Methods}

\section{Study Sites}

We sampled soils at eight sites along two bioclimatic gradients based on elevational transects in Central California, USA (Figure 1A). The Southern Sierra Critical Zone Observatory (SSCZO) experiences a Mediterranean-type climate that traverses the west side of the Sierra Nevada ${ }^{34}$. From west to east, sites increase in elevation, increase in precipitation, and decrease in temperature, and are defined as follows: oak savannah (OS), pine-oak forest (POF), mixed conifer forest (MCF), and subalpine forest (SAF; Figure1A). The White Mountain Elevational Transect (WMET) experiences a semiarid-type climate (i.e., significantly drier than SSCZO, Figure $1 \mathrm{~A}$ ) along the west side of the White-Inyo Range ${ }^{35}$. From west to east, sites also increase in elevation, increase in precipitation, and decrease in temperature and are defined as follows: sagebrush shrubland (SBS), pinyon-juniper woodland (PJW), subalpine shrubland (SAS), and alpine desert grassland (ADG; Figure 1A; see Table S1 for further site characteristics). Soil age across our sites is difficult to determine because of significant aeolian and colluvial deposits ${ }^{36,37}$; however, all soils are derived from granite or granodiorite, and only SAF was glaciated ${ }^{34,35}$. Therefore, we contend that bioclimatic influences dominated differences in soils across the eight sites.

\section{Sample Collection}

Sampling occurred during the dry seasons (late summer, early fall) of 2014 and 2015 . Because the microbial communities in these climates are moisture-limited, the microbial communities at these sites are relatively dormant during the dry season ${ }^{38}$, minimizing the temporal effects of sampling at different times. Four soil pits were dug at each site representing the major topographic features of the landscape (i.e., stratified sampling), and within hours after excavation, soil was collected based on Master and Subordinate genetic horizons. At WMET sites, SBS, PJW, and SAS, there is considerable soil chemical differences between areas under shrubs and the interspace ${ }^{35}$. We sampled only under shrubs to keep sampling consistent with other sites that did not have interspace components. Sampling tools were sanitized with $10 \%$ bleach followed by $70 \%$ ethanol and were used to dig horizontally into the pit face (after clearing away exposed soil). Soils were immediately placed on dry ice for transport back to the laboratory.

\section{Soil Chemistry}

Soil samples were air dried and sieved $(<2 \mathrm{~mm})$ for chemical analyses. We determined elemental concentrations of iron, aluminum, calcium, phosphorus, potassium, magnesium, and silicon using lithium metaborate fusion ${ }^{39}$ measured by inductively-coupled plasma optical-emission spectrometry (ICP-OES; PerkinElmer Optima 5300 DV; University of California, Merced Environmental Analytical Laboratory). We measured organic $C$ and total nitrogen on an elemental analyzer (Costech Analytical ECS 4010 Elemental Analyzer, Costech Analytical Technologies, Inc., Valencia, CA; Stable Isotope Laboratory at the University of California, Merced). Carbonates were removed from WMET sites prior to analysis of organic $\mathrm{C}$ using hydrochloric acid 
fumigation (Harris et al. ${ }^{40}$; no effervescence occurred after $1 \mathrm{M} \mathrm{HCl}$ addition to SSCZO sites, so organic $\mathrm{C}$ was considered equivalent to total $\mathrm{C}$ ). Soil $\mathrm{pH}$ was measured in a 1:2 suspension:solution $\mathrm{w} / \mathrm{v}$ in deionized water and 0.01 $\mathrm{M} \mathrm{CaCl}_{2}$ (Accumet Basic, Model AB15, Fisher Scientific with an Ag/AgCl electrode; Thomas 1996).

\section{Microbial Biomass and Extracellular Enzyme Activity}

We measured microbial biomass C (MBC) by chloroform fumigation-extraction using 10-50 g (depending on sample weight availability and major horizon-greater soil weight was used in deeper horizons) of previously frozen and thawed, field-moist mineral soil ${ }^{42-44}$. Performing chloroform fumigation-extraction on previously frozen soils may slightly affect the absolute values, but the relatively differences among treatments are generally unaffected ${ }^{45}$.

We measured potential extracellular enzyme (EE) activity (i.e., activity not limited by substrate concentrations) of $\beta$-glucosidase (BG), N-acetylglucosaminidase (NAG), and acid phosphatase (AP) fluorometrically following Bell et al. ${ }^{46}$. These three enzymes are considered $\mathrm{C}-, \mathrm{N}$-, and P-acquiring enzymes, respectively. Extracellular enzyme activities were expressed per soil weight (mmol EE activity $\mathrm{kg}^{-1}$ soil h$\left.{ }^{-1}\right)$, SOC (mmol EE activity kg-1 SOC $\left.\mathrm{h}^{-1}\right)$, and MBC (mmol EE activity $\left.\mathrm{kg}^{-1} \mathrm{MBC} \mathrm{h}^{-1}\right)$. These latter two variables are called SOC-normalized and $\mathrm{MBC}-$ normalized, respectively in this paper.

\section{DNA extraction}

We extracted total soil DNA using the MoBio PowerSoil DNA isolation kit (Carlsbad, CA) following the manufacturer's instructions. We extracted DNA from $1 \mathrm{~g}$ of soil using four parallel, replicate extractions $(0.25 \mathrm{~g}$ per extraction), and replicate extracts were pooled onto a single column and eluted in $50 \mu$ for downstream analysis to increase DNA yield. We quantified DNA yields using the Quant-it PicoGreen dsDNA assay kit (Invitrogen, Carlsbad, CA).

\section{PCR amplification, sequencing, and bioinformatics}

Sample libraries were prepared and sequenced at the Environmental Sample Preparation and Sequencing Facility at Argonne National Laboratory (Lemont, IL). For prokaryotes (archaea and bacteria), 16S rRNA genes were amplified in polymerase chain reactions (PCRs) using primers (515F/806R) that target the V4 region of the 16S rRNA gene ${ }^{47}$; for fungi, ITS2 regions were amplified in PCR reactions using ITS9f/ITS4R primers ${ }^{48,49}$ (see the supplemental methods for details on the PCR, sequencing, and bioinformatic procedures).

\section{Statistical Analysis}

All statistical analyses were conducted in R v. $4.0 .2^{50}$, with the betareg ${ }^{51}$, car $^{52}$, Ime $^{53}$, phyloseq ${ }^{54}$, and vegan ${ }^{55}$ packages. For all statistical tests, significance was defined at the $a=0.05$ level. The $R$ code used to conduct statistical analyses and generate figures can be found at https://github.com/nicholascdove/climate_subsoil_microbiome.

Differences in the community composition of the prokaryotes and fungi among sites and depths or horizons were assessed by PERMANOVA ${ }^{56}$. Multiple models were conducted to investigate how community composition is impacted at all sites (Full Model), or the SSCZO and WMET separately. Differences in beta-diversity among 
soil major horizons as well as overall heterogeneity of multivariate dispersions were tested by using the 'betadisper' function in vegan ${ }^{55,57}$. Prokaryote and fungal community compositions were visualized using principal coordinates analysis (PCoA). Environmental vectors were fit onto PCoA ordinations using the 'envfit' function in vegan. For the PERMANOVAs, beta-diversity, and PCoAs, we used Bray-Curtis dissimilarity applied to proportionally normalized data.

The relative control of the direct effects of climate (i.e., MAP and MAT) versus the indirect effects of climate (i.e., soil chemistry) on microbial community composition was assessed using variance partitioning ${ }^{58}$, again using Bray-Curtis dissimilarity applied to proportionally normalized data. For these variance partitioning models, the effect of MAT and MAP were combined to form the variable "climate," and the effect of pH as well as the effect of the molar concentrations of the aforementioned elements were combined to form the variable "soil chemistry." This resulted in variance partitioning models with three independent variables: climate, soil chemistry, and their interaction. The significance of variables was determined using ANOVA and distance-based redundancy analysis (db-RDA, Legendre \& Anderson 1999), sequentially “partialling out” variables.

Significant changes in the relative abundance of individual major microbial taxa with depth, MAT, and MAP

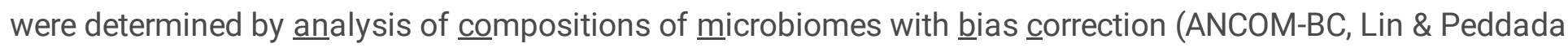
2020). For differences in mycorrhizal relative abundance among sites and major horizons, we used beta regression, which fit the distributions of the dependent variables (i.e., percentages). Where significant, multiple comparisons among sites were assessed by Tukey's HSD.

Multiple mixed-effects models were used to determine the impact of the fixed effects depth, MAT, and MAP on EE activities, with the random effect of pit. These a priori defined models are as follows: 1) $\log _{10}($ enzyme $) \sim$ Depth + (1|Pit), 2) $\log _{10}($ enzyme $) \sim$ Depth + MAT + Depth*MAT + (1|Pit), 3) $\log _{10}($ enzyme $) \sim$ Depth + MAP + Depth*MAP + (1|Pit), and 4) $\log _{10}($ enzyme $) \sim$ Depth + MAT + Depth*MAT + MAP + Depth*MAP + (1|Pit). Enzyme activities were $\log _{10}$ transformed to satisfy assumptions of normality and homoscedasticity.

\section{Results}

Site explains greater variation in microbial community composition than depth

While both site and depth were significant moderators of microbial community composition, site generally explained a greater amount of the variation in the microbial community composition than depth, likely due to differences in climate, soil chemistry, and vegetation (Figure 1; Table 1). However, site and depth significantly interacted in their effect on microbial community composition, such that depth was not a significant moderator of microbial community composition at all sites (Figure S1, Table 1). For prokaryotes, depth was not significant at MCF and POF (Table 1), two of the three wettest sites in our study (Figure 1A), and for fungi, depth was only significant for ADG, SBS, and SAF (Table1).

Major horizon was also a significant factor affecting microbial community composition. While the variation in the microbial community explained by horizon was overall lower than site, Master horizon consistently explained a greater amount of the variation compared to depth increment (Table 1). In fact, horizon was a significant moderator of prokaryote community composition in all sites except MCF (Table 1). However, horizon was only a significant moderator of fungal community composition at ADG (Table 1). On 
average, across all PERMANOVAs, horizon explained $51 \%$ and $89 \%$ more variation than depth increment for prokaryote and fungal community composition, respectively.

Among major horizons, prokaryote beta-diversity was similar across the entire dataset (ANOVA: $F_{2,141}=1.6, p=$ $0.215)$. However, fungal beta-diversity significantly differed by horizon $\left(F_{2,143}=3.8, p=0.026\right)$, with the $\mathrm{A}$ horizon having a significantly higher beta-diversity than the B horizon (Tukey HSD: $p=0.032$ ).

\section{The direct effect of climate on the microbial community declines with depth}

Across elevational gradients and major horizons, both climatic factors (i.e., MAT and MAP) and soil chemistry (i.e., $\mathrm{pH}$ and elemental concentrations) significantly influenced prokaryote (soil chemistry: $F_{11,139}=3.4, p<$ 0.001; climate: $F_{2,139}=4.6, p<0.001$ ) and fungal community composition (soil chemistry: $F_{11,141}=2.4, p<$ 0.001 ; climate: $F_{2,141}=3.1, p<0.001$; Figure $2 \mathrm{~A}$ ). However, the variance explained by soil chemistry was almost three and a half times greater than that of climate. Within each elevational gradient, the relative effect of climate (compared to soil chemistry) decreased with depth (Figure 2B). For prokaryotes, the effect of climate was minimal in the B horizon at the SSCZO, as was the effect of soil chemistry in the A horizon at WMET. For fungi, while the effect of soil chemistry was relatively similar to that of climate in the A horizon, soil chemistry explained three to seven times more variance in the composition than climate in the B horizon.

Response of specific taxa to climate and depth

Overall, the number of differentially abundant taxa were similar (range: 2-9) across elevation gradients and major horizons (Figure 3 and 4). However, certain microbial taxa responded consistently to differences in MAT and MAP, while others followed idiosyncratic patterns across elevation gradients and major horizons (Figure 3 and 4). For example, Actinobacteria and Deltaproteobacteria consistently responded positively to increasing MAT, and Acidobacteria consistently responded positively to increasing MAP (Figure 3). However, Agaricomycetes were positively correlated with MAP and negatively correlated with MAT only in the SSCZO gradient (Figure 4). The same was also true for Verrucomicrobia, but only in the WMET gradient (Figure 3). On the other hand, Archaea were negatively correlated with MAP and correlated positively with MAT, but only in subsurface soil horizons across both gradients (Figure 3).

The relative abundances of many microbial taxa were also significantly impacted by depth, but only in certain sites (Figure S3). For example, the relative abundance of Chloroflexi and Dothideomycetes increased with depth in only two of the eight sites (MCF and ADG for Chloroflexi and OS and SAF for Dothideomycetes, Figure S4). Alternatively, the relative abundance of Agaricomycetes and Alphaproteobacteria decreased with depth in only three (SBS, SAS, ADG) and four sites (OS, POF, SAF, ADG), respectively (Figure S3). The relative abundance of Bacteroidetes consistently decreased with depth, while other taxa had idiosyncratic depth distributions depending on the site (Figure S3). At the two wettest sites, the relative abundance of Peziziomycetes decreased, and in a single site in the WMET gradient (PJW) Pezizomycetes increased. Similarly, the relative abundance of Actinobacteria decreased with depth in the wettest site and increased with depth in the three driest sites (Figure S3).

The influence of depth on the relative abundance of ectomycorrhizal (EM) and arbuscular mycorrhizal (AM) fungi interacted with site (EM: $\left.F_{7,143}=6.1, p<0.001, \mathrm{AM}: F_{7,143}=2.1, p=0.041\right)$, such that depth was a 
significant moderator of EM fungi only at SH (increased) and of AM fungi at SBS and ADG (decreased; Figure S4, Table S2). However, the patterns of EM and AM relative abundances among sites were generally consistent among horizons. The relative abundances of EM fungi were generally higher in forested ecosystems such as POF, MCF, SAF, and PJW. In comparison, the relative abundances of AM fungi were generally higher in grassland ecosystems, such as OS, SBS, and SAS (Figure S4).

The impact of climate on extracellular enzyme activity depends on normalization method and depth

Extracellular enzyme activity per unit soil weight consistently decreased with soil depth (Figure S5). Still, when normalized by mol MBC or soil organic C (SOC), EE activity increased with soil depth (Table 2). Per unit soil weight, EE activity was generally unrelated to climatic factors when controlling for soil depth (Table 2). However, normalized by mol MBC, the activities of NAG and AP were positively influenced by increasing MAT and MAP, and normalized by SOC, the activities of NAG and AP were positively influenced by increasing MAT (Table 2). However, the effect of these climate variables interacted with soil depth, where the effect of both MAP and MAT diminished with increasing soil depth (Table 2). For BG per mol MBC, there was only a main, positive effect of MAP, which interacted negatively with soil depth; BG activity per mol SOC was not influenced by the main effects of MAT and MAP. However, the effect of soil depth on BG activity per mol MBC decreased with increasing MAP (Table 2).

Substituting the effect of major horizon for the effect of depth increment on EE activities revealed similar patterns, with major horizon being a strong moderator of EE activity (Table S3). However, for BG and NAG activities (across all normalization methods), the effect of horizon consistently interacted with MAT. Similar to models including soil depth increment, the effect of MAT decreased in subsoil horizons (Figure S6S8).

\section{Discussion}

It is becoming increasingly evident that microorganisms in the subsoil play important roles in soil $\mathrm{C}$ and nutrient cycling 5,25,29,31, yet our understanding on the controls of microbial communities in the subsoil is limited. Here, we not only show that microbial community composition changes with depth, but also that the impact of climate, which strongly controls the surface soil microbial community composition, decreases in subsoil horizons ${ }^{7,8,61,62}$. Furthermore, we find that certain microbial taxa change in relative abundance over large temperature and precipitation gradients only in specific soil horizons, highlighting the depth dependence of the climatic controls on microbial community composition.

Consistent with our hypothesis, the indirect effects of climate (i.e., soil physical and chemistry properties) became a more dominant control of microbial community composition with soil depth. At depth, seasonal and diurnal fluctuations in temperature and moisture are muted ${ }^{23,24}$, such that temperature and moisture extremes common in the surface that would likely select for certain microbial taxa ${ }^{63,64}$ may not occur in the subsoil. Instead, edaphic factors such as organic $C$ limitation and changes in soil nutrients with depth $4,28,65$ were apparently stronger moderators of subsoil microbial community composition. Our results support this assertion as oligotrophic and lithotrophic microorganisms adapted to low organic $\mathrm{C}$ availabilities increased with depth. For example, Bacteroidetes, which are generally considered copiotrophic ${ }^{66}$, decreased 
with soil depth, while Nitrospirae and Archaea, which are commonly lithotrophic ${ }^{67}$, increased with soil depth. Conceptually, we propose that the direct influence of climate extends from the atmosphere into the surface while the subsoil is influenced by the longer-term effects of climate, namely soil chemistry. This suggests that extrapolating microbial community composition based solely on climate variables when the climate is changing may not be appropriate in deeper soil layers.

While the effect of climate on microbial communities diminished in the subsoil, there were still microbial taxa that consistently responded to changes in climate across soil horizons. For instance, Actinobacteria consistently increased in relative abundance with increasing temperatures. This is consistent with previous research in the surface soil showing Actinobacteria phylotypes have greater relative abundances at warmer sites and respond positively to increasing temperature in laboratory incubations ${ }^{13}$. Furthermore, in field warming studies, Actinobacteria also increase in relative abundance in the surface in response to warming ${ }^{68,69}$ and subsoil ${ }^{25}$. In contrast, Archaea generally increased in relative abundance with increasing temperatures only in the subsoil. The relative abundance of Archaea does not generally correlate positively with temperature in the surface soil ${ }^{70}$, but have been shown to increase in relative abundances with permafrost warming in deeper layers $^{71}$. Our results show that Archaea respond positively to temperature at depth in temperate forests as well. Together, these results suggest that characterizing microbial responses to temperature is depth-dependent, underscoring the need of whole profile warming studies to elucidate the response of microbial communities to increased temperatures (e.g., Johnston et al. ${ }^{71}$, Dove et al. ${ }^{25}$ ).

The depth dependence of climate impacts on microbial community composition also extended to microbial activity. We found that the impact of depth on microbial activity interacted with climate such that the positive effect of MAT and MAP on MBC- and SOC-normalized EE activity was muted in deeper soil horizons. This suggests that while EE activity on a MBC or SOC basis is positively correlated with MAT and MAP6 ${ }^{6}$ this may not be the case in deeper soils. It is possible that greater clay stabilization of EE activities at depth may have reduced the influence of climate on microbial activity because higher microbial activities would reflect soil mineralogy rather than biology $5,72,73$. Hence, our results provide another line of evidence for the diminished effect of climate on subsoil microbial communities.

It was somewhat surprising that site explained over an order of magnitude more variation in microbial community composition than depth because many physical and chemical properties of soil change dramatically throughout the soil profile. For instance, organic $\mathrm{C}$ concentration decreases with increasing soil depth $^{4}$, selecting for microorganisms capable of utilizing a myriad of substrates ${ }^{25}$ or even alternative energy sources, such as $\mathrm{CO}^{1}$. Hence, the effect of soil depth on microbial community composition has been shown to be as strong as the effect of location ${ }^{74}$. However, over relatively broader ecological gradients, the effect of site can become stronger than soil depth ${ }^{1}$. This discrepancy is probably the result of greater soil chemical and climatic heterogeneity across sites, which likely explains the findings in this study as our sites spanned multiple bioclimatic envelopes (Figure 1A) and included large differences in soil chemistry. For example, the relative abundance of EM and AM largely correlated with whether the ecosystem was tree- or grass-dominated and was generally not influenced by depth. It is also possible that microbial dispersal in deeper soil layers contributed to the greater effect of site than soil depth. If the lateral movement of soil microbes across large distances occurs primarily aboveground ${ }^{75,76}$, then the species pool for subsurface colonization is constrained by surface soil 
conditions. In other words, subsoil microbial communities need to pass through two environmental filters: the condition of the surface soil and the subsoil counterpart. Indeed, in a temperate grassland ecosystem, dispersal limitation across $2 \mathrm{~km}$ and selective determinism was found to increase with soil depth ${ }^{77}$. In the context of a changing climate, this apparent dispersal limitation suggests that changes to the community composition of the subsoil will likely follow that of the surface soil.

Our finding that major soil genetic horizon explained a greater proportion of the variation in microbial community composition than depth increment suggests that depth-resolved microbial ecology should sample based on Master or Subordinate horizons when possible. Commonly, soils are sampled by depth increment rather than major horizon ${ }^{1,5,25}$, because delineating genetic horizons necessitates an in-depth understanding of physical and chemical nature of the soil profile and technical expertise. Furthermore, soil characterization is often only possible through full pit excavation rather than deep soil cores sampled from the surface (i.e., how deeper soil layers are commonly sampled in microbial ecology). Here, we show that soil chemistry is a strong moderator of microbial community composition. Therefore, because major horizons are in part delineated by soil chemistry ${ }^{78}$, it is unsurprising that genetic horizons explained a greater proportion of the variation in microbial community composition than depth increment. It is also possible that genetic horizon explained a greater proportion of the variation because, unlike depth increment, it is a categorical variable that can better describe often observed nonmonotonic changes in the relative abundance of microbial taxa with depth (Figure S3). Therefore, we recommend studies of microbial communities throughout the soil profile sample based on genetic horizons rather than depth increment whenever possible.

The differences in climate exhibited in this study are relatively greater than what is expected within the next century due to climate change ${ }^{79}$. However, these observational findings corroborate recent experimental findings suggesting that the microbial response to increased temperatures is somewhat subdued at depth ${ }^{25}$. Additionally, unlike experimental warming, these results incorporate the longer term nature of climate effects, including both the direct and indirect (i.e., changes in soil chemistry and vegetation) effects of increased temperatures. Bradford et al. ${ }^{80}$ proposed that microbial temperature acclimation might mitigate enhanced microbial respiration due to increased temperatures with climate change. However, our main finding that the direct impacts of climate are reduced at depth suggests that deep soil microbial communities may lag in their acclimation to new temperatures, potentially allowing for continued enhanced microbial respiration rates that further increase atmospheric $\mathrm{CO}_{2}$ levels.

\section{Declarations}

Data availability. All sequence data can be accessed through the sequence read archive under Bioproject PRJNA743681. Soil chemistry data will be archived in the Dryad repository upon acceptance, and the data DOI will be included at the end of the article.

Author Contributions. NCD - study design, field sampling, laboratory work, data analysis, manuscript writing and revision. MEB - study design, field sampling, laboratory work, manuscript revision. KCM - study design, field sampling, laboratory work manuscript revision. RCG - study design, field sampling, manuscript revision. AAB - study design, field sampling, manuscript revision. $\mathrm{SCH}$ - study design, field sampling, manuscript revision. 
The United States Government retains and the publisher, by accepting the article for publication, acknowledges that the United States Government retains a non-exclusive, paid-up, irrevocable, world-wide license to publish or reproduce the published form of this manuscript, or allow others to do so, for United States Government purposes. The Department of Energy will provide public access to these results of federally sponsored research in accordance with the DOE Public Access Plan.

\section{ACKNOWLEDGEMENTS}

We thank M. Brumbacker, O. Elias, S. Glaser, E. lencarelli, P. Klotz, D. DeNeve Weeks, and M. Yee Vang for their extensive field and laboratory assistance. The research was supported by the Southern Sierra Critical Zone Observatory (SSCZO; EAR-0725097, 1239521, and 1331939), University of California Merced Graduate Fellowship Awards (to N. Dove and M. Barnes), a Southern California Edison Graduate Fellowship (to N. Dove), Institute for the Study of Ecological Effects of Climate Impacts Fellowship and Grant (to M. Barnes), and a Mildred E. Mathias Grant (to M. Barnes). Additionally, postdoctoral development funds from Oak Ridge National Laboratory also supported N. Dove during the writing of this manuscript (Oak Ridge National Laboratory is managed by UT-Battelle, LLC, for the U.S. DOE under contract DEAC05-000R22725).

\section{References}

1. Brewer, T. E. et al. Ecological and Genomic Attributes of Novel Bacterial Taxa That Thrive in Subsurface Soil Horizons. mBio 10, e01318-19 (2019).

2. Brubaker, S. C., Jones, A. J., Lewis, D. T. \& Frank, K. Soil Properties Associated with Landscape Position. Soil Science Society of America Journal 57, 235-239 (1993).

3. Richter, D. D. \& Markewitz, D. How Deep Is Soil? BioScience 45, 600-609 (1995).

4. Rumpel, C. \& Kögel-Knabner, I. Deep soil organic matter-a key but poorly understood component of terrestrial C cycle. Plant Soil 338, 143-158 (2010).

5. Dove, N. C. et al. Continental-scale patterns of extracellular enzyme activity in the subsoil: an overlooked reservoir of microbial activity. Environ. Res. Lett. 15, 1040a1 (2020).

6. Sinsabaugh, R. L. et al. Stoichiometry of soil enzyme activity at global scale. Ecology Letters 11, 12521264 (2008).

7. Tedersoo, L. et al. Global diversity and geography of soil fungi. Science 346, (2014).

8. Thompson, L. R. et al. A communal catalogue reveals Earth's multiscale microbial diversity. Nature advance online publication, (2017).

9. Chapin, F. S., Matson, P. A. \& Vitousek, P. Principles of Terrestrial Ecosystem Ecology. (Springer Science \& Business Media, 2011).

10. Bárcenas-Moreno, G., Gómez-Brandón, M., Rousk, J. \& Bååth, E. Adaptation of soil microbial communities to temperature: comparison of fungi and bacteria in a laboratory experiment. Global Change 
Biology 15, 2950-2957 (2009).

11. Wallenstein, M., Allison, S. D., Ernakovich, J., Steinweg, J. M. \& Sinsabaugh, R. Controls on the Temperature Sensitivity of Soil Enzymes: A Key Driver of In Situ Enzyme Activity Rates. in Soil Enzymology (eds. Shukla, G. \& Varma, A.) 245-258 (Springer, 2011). doi:10.1007/978-3-642-14225-3_13.

12. German, D. P., Marcelo, K. R. B., Stone, M. M. \& Allison, S. D. The Michaelis-Menten kinetics of soil extracellular enzymes in response to temperature: a cross-latitudinal study. Glob Change Biol 18, 1468-1479 (2012).

13. Oliverio, A. M., Bradford, M. A. \& Fierer, N. Identifying the microbial taxa that consistently respond to soil warming across time and space. Global Change Biology 23, 2117-2129 (2017).

14. Jenny, H. Factors of soil formation. (1941).

15. Parton, W. J., Scurlock, J. M. O., Ojima, D. S., Schimel, D. S. \& Hall, D. O. Impact of climate change on grassland production and soil carbon worldwide. Global Change Biology 1, 13-22 (1995).

16. Jenny, H. The Soil Resource: Origin and Behavior. (Springer Science \& Business Media, 1980).

17. Fierer, N. \& Jackson, R. B. The diversity and biogeography of soil bacterial communities. PNAS 103, 626-631 (2006).

18. Lauber, C. L., Hamady, M., Knight, R. \& Fierer, N. Pyrosequencing-Based Assessment of Soil pH as a Predictor of Soil Bacterial Community Structure at the Continental Scale. Appl. Environ. Microbiol. 75, 51115120 (2009).

19. Slessarev, E. W. et al. Water balance creates a threshold in soil pH at the global scale. Nature 540,567569 (2016).

20. Brovkin, V. Climate-vegetation interaction. J. Phys. IV France 12, 57-72 (2002).

21. Aerts, R. Climate, Leaf Litter Chemistry and Leaf Litter Decomposition in Terrestrial Ecosystems: A Triangular Relationship. Oikos 79, 439-449 (1997).

22. Djukic, I. et al. Early stage litter decomposition across biomes. Science of The Total Environment 628629, 1369-1394 (2018).

23. Shiozawa, S. \& Campbell, G. S. Soil thermal conductivity. Remote Sensing Reviews 5, 301-310 (1990).

24. Verhoef, A., Fernández-Gálvez, J., Diaz-Espejo, A., Main, B. E. \& El-Bishti, M. The diurnal course of soil moisture as measured by various dielectric sensors: Effects of soil temperature and the implications for evaporation estimates. Journal of Hydrology 321, 147-162 (2006).

25. Dove, N. C., Torn, M. S., Hart, S. C. \& Taş, N. Metabolic capabilities mute positive response to direct and indirect impacts of warming throughout the soil profile. Nature Communications 12, 2089 (2021). 
26. Bai, W., Wang, G., Xi, J., Liu, Y. \& Yin, P. Short-term responses of ecosystem respiration to warming and nitrogen addition in an alpine swamp meadow. European Journal of Soil Biology 92, 16-23 (2019).

27. Yost, J. L. \& Hartemink, A. E. How deep is the soil studied - an analysis of four soil science journals. Plant Soil (2020) doi:10.1007/s11104-020-04550-z.

28. Jobbágy, E. G. \& Jackson, R. B. The vertical distribution of soil organic carbon and its relation to climate and vegetation. Ecological Applications 10, 423-436 (2000).

29. Hicks Pries, C. E., Castanha, C., Porras, R. C. \& Torn, M. S. The whole-soil carbon flux in response to warming. Science 355, 1420-1423 (2017).

30. Jones, D. L. et al. Microbial competition for nitrogen and carbon is as intense in the subsoil as in the topsoil. Soil Biology and Biochemistry 117, 72-82 (2018).

31. Ofiti, N. O. E. et al. Warming promotes loss of subsoil carbon through accelerated degradation of plantderived organic matter. Soil Biology and Biochemistry 156, 108185 (2021).

32. Soong, J. L. et al. Five years of whole-soil warming led to loss of subsoil carbon stocks and increased C02 efflux. Science Advances 7, eabd1343 (2021).

33. Nottingham, A. T. et al. Microbes follow Humboldt: temperature drives plant and soil microbial diversity patterns from the Amazon to the Andes. Ecology 99, 2455-2466 (2018).

34. O'Geen, A. (Toby) et al. Southern Sierra Critical Zone Observatory and Kings River Experimental Watersheds: A Synthesis of Measurements, New Insights, and Future Directions. Vadose Zone Journal 17, 180081 (2018).

35. Frisbie, J. A. Soil Organic Carbon Storage and Aggregate Stability in an Arid Mountain Range, White Mountains, CA. (UC Riverside, 2014).

36. Marchand, D. E. Soil Contamination in the White Mountains, Eastern California. GSA Bulletin 81, 24972506 (1970).

37. Aciego, S. M. et al. Dust outpaces bedrock in nutrient supply to montane forest ecosystems. Nature Communications 8, 14800 (2017).

38. Dove, N. C., Safford, H. D., Bohlman, G. N., Estes, B. L. \& Hart, S. C. High-severity wildfire leads to multidecadal impacts on soil biogeochemistry in mixed-conifer forests. Ecological Applications 30, e02072 (2020).

39. Lajtha, K., Driscoll, C. T., Jarrell, W. M. \& Elliot, E. T. Phosphorus Characterization and Total Element Analysis. in Standard Soil Methods for Long-Term Ecological Research (eds. Robertson, G. P., Coleman, D. C., Bledsoe, C. S. \& Sollins, P.) 115-142 (Oxford University Press, 1999).

40. Harris, D., Horwáth, W. R. \& Kessel, C. van. Acid fumigation of soils to remove carbonates prior to total organic carbon or CARBON-13 isotopic analysis. Soil Science Society of America Journal 65, 1853-1856 (2001). 
41. Thomas, G. W. Soil pH and soil acidity. in Methods of Soil Analysis, Part 3: Chemical Methods (eds. Sparks, D. L. et al.) 475- (Soil Science Society of America, American Society of Agronomy, 1996).

42. Vance, E. D., Brookes, P. C. \& Jenkinson, D. S. An extraction method for measuring soil microbial biomass C. Soil Biology and Biochemistry 19, 703-707 (1987).

43. Hart, S. C. \& Firestone, M. K. Forest floor-mineral soil interactions in the internal nitrogen cycle of an oldgrowth forest. Biogeochemistry 12, 103-127 (1991).

44. Haubensak, K. A., Hart, S. C. \& Stark, J. M. Influences of chloroform exposure time and soil water content on $\mathrm{C}$ and $\mathrm{N}$ release in forest soils. Soil Biology and Biochemistry 34, 1549-1562 (2002).

45. Stenberg, B. et al. Microbial biomass and activities in soil as affected by frozen and cold storage. Soil Biology and Biochemistry 30, 393-402 (1998).

46. Bell, C. W. et al. High-throughput Fluorometric Measurement of Potential Soil Extracellular Enzyme Activities. Journal of Visualized Experiments (2013) doi:10.3791/50961.

47. Parada, A. E., Needham, D. M. \& Fuhrman, J. A. Every base matters: assessing small subunit rRNA primers for marine microbiomes with mock communities, time series and global field samples. Environmental Microbiology 18, 1403-1414 (2016).

48. Ihrmark, K. et al. New primers to amplify the fungal ITS2 region - evaluation by 454-sequencing of artificial and natural communities. FEMS Microbiol Ecol 82, 666-677 (2012).

49. Smith, D. P. \& Peay, K. G. Sequence depth, not PCR replication, improves ecological inference from next generation DNA sequencing. PLoS ONE 9, e90234 (2014).

50. R Development Core Team. R: A language and environment for statistical computing. (R Foundation for Statistical Computing, 2008).

51. Cribari-Neto, F. \& Zeileis, A. Beta Regression in R. Journal of Statistical Software 34, 1-24 (2010).

52. Fox, J. \& Weisberg, S. An $\{R\}$ Companion to Applied Regression. (Sage, 2011).

53. Bates, D., Maechler, M., Bolker, B. \& Walker, S. Fitting Linear Mixed-Effects Models Using Ime4. Journal of Statistical Software 67, 1-48 (2015).

54. McMurdie, P. J. \& Holmes, S. phyloseq: An R Package for Reproducible Interactive Analysis and Graphics of Microbiome Census Data. PLOS ONE 8, e61217 (2013).

55. Oksanen, J. et al. vegan: Community Ecology Package. (2013).

56. Anderson, M. J. A new method for non-parametric multivariate analysis of variance. Austral Ecology 26, 32-46 (2001). 
57. Anderson, M. J., Ellingsen, K. E. \& McArdle, B. H. Multivariate dispersion as a measure of beta diversity. Ecology Letters 9, 683-693 (2006).

58. Legendre, P. \& Cáceres, M. D. Beta diversity as the variance of community data: dissimilarity coefficients and partitioning. Ecology Letters 16, 951-963 (2013).

59. Legendre, P. \& Anderson, M. J. Distance-Based Redundancy Analysis: Testing Multispecies Responses in Multifactorial Ecological Experiments. Ecological Monographs 69, 1-24 (1999).

60. Lin, H. \& Peddada, S. D. Analysis of compositions of microbiomes with bias correction. Nature Communications 11, 3514 (2020).

61. Delgado-Baquerizo, M. et al. A global atlas of the dominant bacteria found in soil. Science 359, 320-325 (2018).

62. Kanzaki, Y. \& Takemoto, K. Diversity of Dominant Soil Bacteria Increases with Warming Velocity at The Global Scale. Diversity 13, 120 (2021).

63. Russell, N. J. et al. Cold adaptation of microorganisms. Philosophical Transactions of the Royal Society of London. B, Biological Sciences 326, 595-611 (1990).

64. Chanal, A. et al. The desert of Tataouine: an extreme environment that hosts a wide diversity of microorganisms and radiotolerant bacteria. Environmental Microbiology 8, 514-525 (2006).

65. Jobbágy, E. G. \& Jackson, R. B. The distribution of soil nutrients with depth: Global patterns and the imprint of plants. Biogeochemistry 53, 51-77 (2001).

66. Fierer, N., Bradford, M. A. \& Jackson, R. B. Toward an Ecological Classification of Soil Bacteria. Ecology 88, 1354-1364 (2007).

67. Offre, P., Spang, A. \& Schleper, C. Archaea in Biogeochemical Cycles. Annual Review of Microbiology 67, 437-457 (2013).

68. Xiong, J. et al. Characterizing changes in soil bacterial community structure in response to short-term warming. FEMS Microbiol Ecol 89, 281-292 (2014).

69. DeAngelis, K. M. et al. Long-term forest soil warming alters microbial communities in temperate forest soils. Front Microbiol 6, (2015).

70. Hayden, H. L. et al. Changes in the microbial community structure of bacteria, archaea and fungi in response to elevated $\mathrm{CO} 2$ and warming in an Australian native grassland soil. Environmental Microbiology 14, $3081-3096$ (2012).

71. Johnston, E. R. et al. Responses of tundra soil microbial communities to half a decade of experimental warming at two critical depths. PNAS 116, 15096-15105 (2019). 
72. Sarkar, J. M., Leonowicz, A. \& Bollag, J.-M. Immobilization of enzymes on clays and soils. Soil Biology and Biochemistry 21, 223-230 (1989).

73. Burns, R. G. et al. Soil enzymes in a changing environment: Current knowledge and future directions. Soil Biology and Biochemistry 58, 216-234 (2013).

74. Eilers, K. G., Debenport, S., Anderson, S. \& Fierer, N. Digging deeper to find unique microbial communities: The strong effect of depth on the structure of bacterial and archaeal communities in soil. Soil Biology and Biochemistry 50, 58-65 (2012).

75. Kellogg, C. A. \& Griffin, D. W. Aerobiology and the global transport of desert dust. Trends in Ecology \& Evolution 21, 638-644 (2006).

76. Martiny, J. B. H. et al. Microbial biogeography: putting microorganisms on the map. Nature Reviews Microbiology 4, 102-112 (2006).

77. Du, X. et al. Steeper spatial scaling patterns of subsoil microbiota are shaped by deterministic assembly process. Molecular Ecology 30, 1072-1085 (2021).

78. Fanning, D. S. \& Fanning, M. C. B. Soil morphology, genesis and classification. Soil morphology, genesis and classification. (1989).

79. IPCC. Climate Change 2014: Synthesis Report. Contribution of Working Groups I, II and III to the Fifth Assessment Report of the Intergovernmental Panel on Climate Change. 1-151 (2014).

80. Bradford, M. A. et al. Thermal adaptation of soil microbial respiration to elevated temperature. Ecology Letters 11, 1316-1327 (2008).

\section{Tables}

Table 1: The $\mathrm{R}^{2}$ of "horizon" or "depth" in prokaryote and fungi PERMANOVA models when either was included. The Full, SSCZO, and WMET models also included "site" and the interaction of "horizon" and "site" or "depth" and "site" as factors. Bolded values indicate significance of the factor $(p<0.05)$. 


\begin{tabular}{|c|c|c|c|c|c|c|c|c|c|c|}
\hline & Prokan & & & & & Fungi & & & & \\
\hline \multirow[t]{2}{*}{ Model } & Site & Horizon & Depth & Site* & Site* & Site & Horizon & Depth & Site* & Site* \\
\hline & & & & Horizon & Depth & & & & Horizon & Depth \\
\hline Full & 0.346 & 0.039 & 0.024 & 0.122 & 0.089 & 0.221 & 0.021 & 0.010 & 0.109 & 0.068 \\
\hline ssczo & 0.278 & 0.073 & 0.045 & 0.104 & 0.069 & 0.143 & 0.036 & 0.019 & 0.086 & 0.061 \\
\hline os & & 0.255 & 0.164 & & & & 0.167 & 0.089 & & \\
\hline POF & & 0.156 & 0.137 & & & & 0.096 & 0.096 & & \\
\hline MCF & & 0.189 & 0.126 & & & & 0.160 & 0.072 & & \\
\hline SAF & & 0.375 & 0.201 & & & & 0.145 & 0.110 & & \\
\hline WMET & 0.255 & 0.082 & 0.051 & 0.102 & 0.085 & 0.218 & 0.049 & 0.024 & 0.101 & 0.061 \\
\hline SBS & & 0.212 & 0.155 & & & & 0.205 & 0.124 & & \\
\hline PJW & & 0.238 & 0.195 & & & & 0.147 & 0.110 & & \\
\hline SAS & & 0.387 & 0.206 & & & & 0.249 & 0.118 & & \\
\hline ADG & & 0.218 & 0.182 & & & & 0.296 & 0.091 & & \\
\hline
\end{tabular}

Table 2: Coefficients of competing mixed effects models of enzyme activity $(\mu \mathrm{mol})$ normalized by soil weight, microbial biomass carbon (MBC), and soil organic carbon (SOC). Bolded coefficients represent significant ( $p<$ $0.05)$ fixed effects. Key: $B G=\beta$-glucosidase, $N A G=N$-acetylglucosamine, $A P=$ acid phosphatase, $M A T=$ mean annual air temperature $\left({ }^{\circ} \mathrm{C}\right), \mathrm{MAP}=$ mean annual precipitation $(\mathrm{mm})$. 


Enzyme Model* Depth MAT Depth*MAT MAP Depth*MAP AIC

\begin{tabular}{|c|c|c|c|c|c|c|c|c|}
\hline \multirow{4}{*}{\multicolumn{2}{|c|}{$\mu \mathrm{mol} \mathrm{kg}{ }^{-1}$ soil }} & 1 & $\begin{array}{l}-3.43 E- \\
03\end{array}$ & & & & & 228.77 \\
\hline & & 2 & $\begin{array}{l}-6.21 \mathrm{E}- \\
03\end{array}$ & $\begin{array}{l}-2.13 \mathrm{E}- \\
02\end{array}$ & $2.74 \mathrm{E}-04$ & & & 252.69 \\
\hline & & 3 & $\begin{array}{l}-6.28 \mathrm{E}- \\
04\end{array}$ & & & $\begin{array}{l}2.11 \mathrm{E}- \\
04\end{array}$ & $-3.84 \mathrm{E}-06$ & 270.20 \\
\hline & & 4 & $\begin{array}{l}-3.90 \mathrm{E}- \\
03\end{array}$ & $\begin{array}{l}-2.11 \mathrm{E}- \\
02\end{array}$ & $2.55 \mathrm{E}-04$ & $\begin{array}{l}2.09 \mathrm{E}- \\
04\end{array}$ & $-2.96 \mathrm{E}-06$ & 294.35 \\
\hline & NAG & 1 & $\begin{array}{l}-2.60 \mathrm{E}- \\
03\end{array}$ & & & & & 194.22 \\
\hline & & 2 & $\begin{array}{l}-1.70 \mathrm{E}- \\
03\end{array}$ & $\begin{array}{l}1.58 \mathrm{E}- \\
02\end{array}$ & $-1.08 \mathrm{E}-04$ & & & 219.63 \\
\hline & & 3 & $\begin{array}{l}1.64 \mathrm{E}- \\
03\end{array}$ & & & $\begin{array}{l}5.15 E- \\
04\end{array}$ & $-6.05 E-06$ & 232.62 \\
\hline & & 4 & $\begin{array}{l}3.56 \mathrm{E}- \\
03\end{array}$ & $\begin{array}{l}1.90 \mathrm{E}- \\
02\end{array}$ & -1.57E-04 & $\begin{array}{l}5.45 \mathrm{E}- \\
04\end{array}$ & $-6.71 \mathrm{E}-06$ & 257.57 \\
\hline & AP & 1 & $\begin{array}{l}-1.89 \mathrm{E}- \\
03\end{array}$ & & & & & 162.00 \\
\hline & & 2 & $\begin{array}{l}-2.28 \mathrm{E}- \\
03\end{array}$ & $\begin{array}{l}1.02 \mathrm{E}- \\
02\end{array}$ & 1.87E-05 & & & 188.16 \\
\hline & & 3 & $\begin{array}{l}2.00 \mathrm{E}- \\
03\end{array}$ & & & $\begin{array}{l}2.61 \mathrm{E}- \\
04\end{array}$ & $-5.29 E-06$ & 201.64 \\
\hline & & 4 & $\begin{array}{l}2.00 \mathrm{E}- \\
03\end{array}$ & $\begin{array}{l}1.09 \mathrm{E}- \\
02\end{array}$ & $-2.36 \mathrm{E}-05$ & $\begin{array}{l}2.46 \mathrm{E}- \\
04\end{array}$ & $-5.16 E-06$ & 228.20 \\
\hline
\end{tabular}

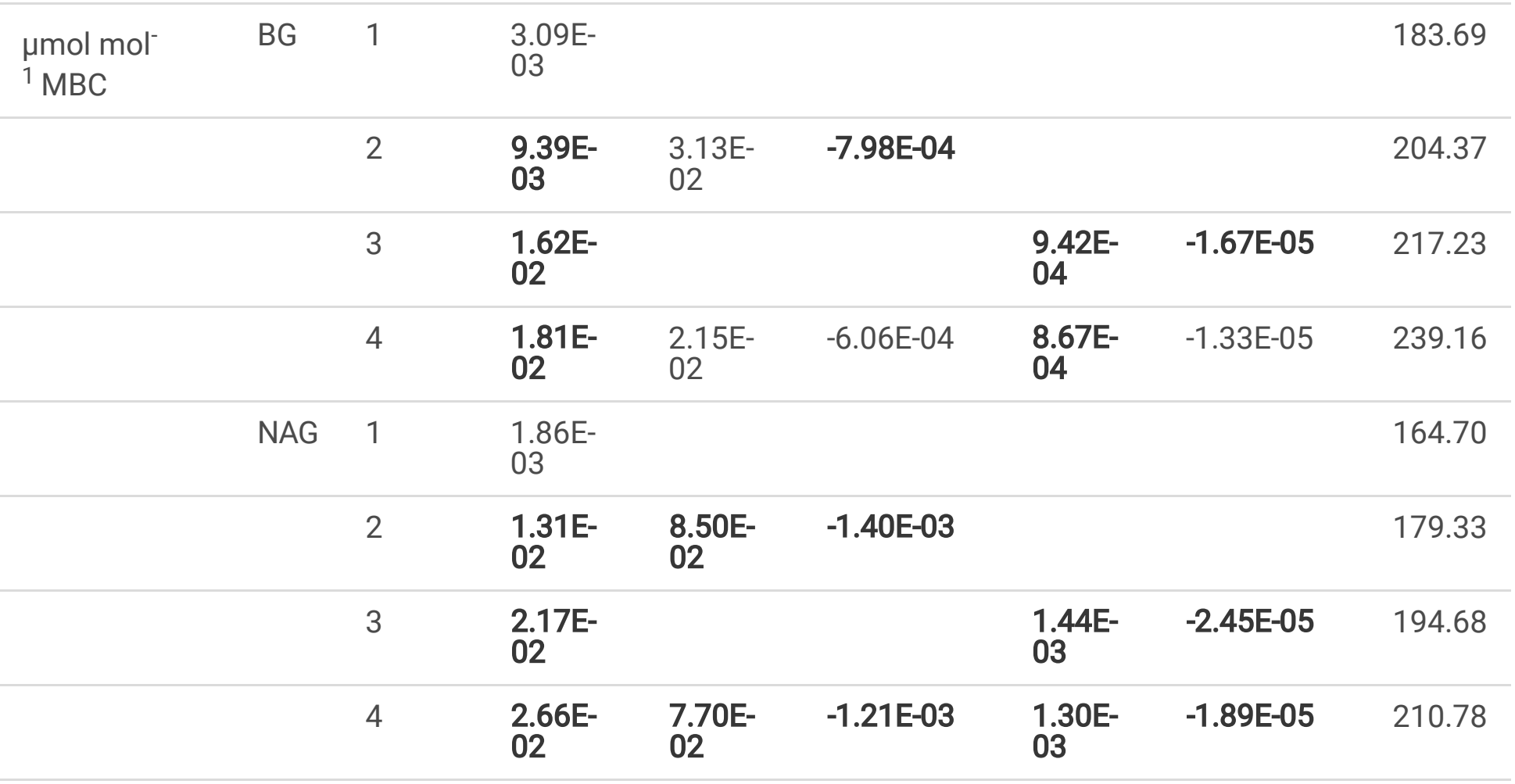




\begin{tabular}{|c|c|c|c|c|c|c|c|c|}
\hline & AP & 1 & $\begin{array}{l}5.14 E- \\
03\end{array}$ & & & & & 184.55 \\
\hline & & 2 & $\begin{array}{l}1.39 \mathrm{E}- \\
02\end{array}$ & $\begin{array}{l}6.80 \mathrm{E}- \\
02\end{array}$ & $-1.14 E-03$ & & & 196.66 \\
\hline & & 3 & $\begin{array}{l}2.21 \mathrm{E}- \\
02\end{array}$ & & & $\begin{array}{l}9.88 \mathrm{E}- \\
04\end{array}$ & $-2.14 E-05$ & 214.32 \\
\hline & & 4 & $\begin{array}{l}2.47 \mathrm{E}- \\
02\end{array}$ & $\begin{array}{l}5.80 \mathrm{E}- \\
02\end{array}$ & $-8.78 E-04$ & $\begin{array}{l}7.86 E- \\
04\end{array}$ & $-1.63 E-05$ & 230.14 \\
\hline $\begin{array}{l}\mu \mathrm{mol} \mathrm{mol} \\
1 \mathrm{~s} \Omega\end{array}$ & $B G$ & 1 & $\begin{array}{l}4.59 \mathrm{E}- \\
03\end{array}$ & & & & & 262.28 \\
\hline & & 2 & $\begin{array}{l}5.92 E- \\
03\end{array}$ & $\begin{array}{l}-1.74 E- \\
03\end{array}$ & $-1.13 E-04$ & & & 287.61 \\
\hline & & 3 & $\begin{array}{l}1.47 E- \\
02\end{array}$ & & & $\begin{array}{l}-7.21 \mathrm{E}- \\
05\end{array}$ & $-1.27 E-05$ & 289.92 \\
\hline & & 4 & $\begin{array}{l}1.79 \mathrm{E}- \\
02\end{array}$ & $\begin{array}{l}5.76 \mathrm{E}- \\
03\end{array}$ & $-2.32 E-04$ & $\begin{array}{l}-6.86 E- \\
05\end{array}$ & $-1.35 E-05$ & 314.59 \\
\hline & NAG & 1 & $\begin{array}{l}4.43 E- \\
03\end{array}$ & & & & & 230.56 \\
\hline & & 2 & $\begin{array}{l}9.67 E- \\
03\end{array}$ & $\begin{array}{l}4.64 E- \\
02\end{array}$ & $-5.21 E-04$ & & & 249.31 \\
\hline & & 3 & $\begin{array}{l}1.54 E- \\
02\end{array}$ & & & $\begin{array}{l}2.67 E- \\
04\end{array}$ & $-1.42 E-05$ & 261.85 \\
\hline & & 4 & $\begin{array}{l}2.49 \mathrm{E}- \\
02\end{array}$ & $\begin{array}{l}5.56 \mathrm{E}- \\
02\end{array}$ & $-7.05 E-04$ & $\begin{array}{l}3.63 \mathrm{E}- \\
04\end{array}$ & $-1.73 E-05$ & 275.54 \\
\hline & AP & 1 & $\begin{array}{l}6.40 E- \\
03\end{array}$ & & & & & 219.41 \\
\hline & & 2 & $\begin{array}{l}1.07 \mathrm{E}- \\
02\end{array}$ & $\begin{array}{l}3.03 E- \\
02\end{array}$ & $-4.21 E-04$ & & & 237.72 \\
\hline & & 3 & $\begin{array}{l}1.68 E- \\
02\end{array}$ & & & $\begin{array}{l}-6.64 \mathrm{E}- \\
05\end{array}$ & $-1.32 E-05$ & 239.63 \\
\hline & & 4 & $\begin{array}{l}2.29 \mathrm{E}- \\
02\end{array}$ & $\begin{array}{l}3.50 \mathrm{E}- \\
02\end{array}$ & $-1.43 E-05$ & $\begin{array}{l}-8.81 \mathrm{E}- \\
05\end{array}$ & $-1.43 E-05$ & 253.38 \\
\hline \multicolumn{9}{|c|}{$\star 1=\log _{10}($ enzyme $) \sim$ Depth $+(1 \mid \mathrm{Pit})$} \\
\hline \multicolumn{9}{|c|}{$2=\log _{10}($ enzyme $) \sim$ Depth + MAT + Depth*MAT + (1|Pit $)$} \\
\hline \multicolumn{9}{|c|}{$3=\log _{10}($ enzyme $) \sim$ Depth + MAP + Depth $\star M A P+(1 \mid$ Pit $)$} \\
\hline
\end{tabular}




\section{Figures}
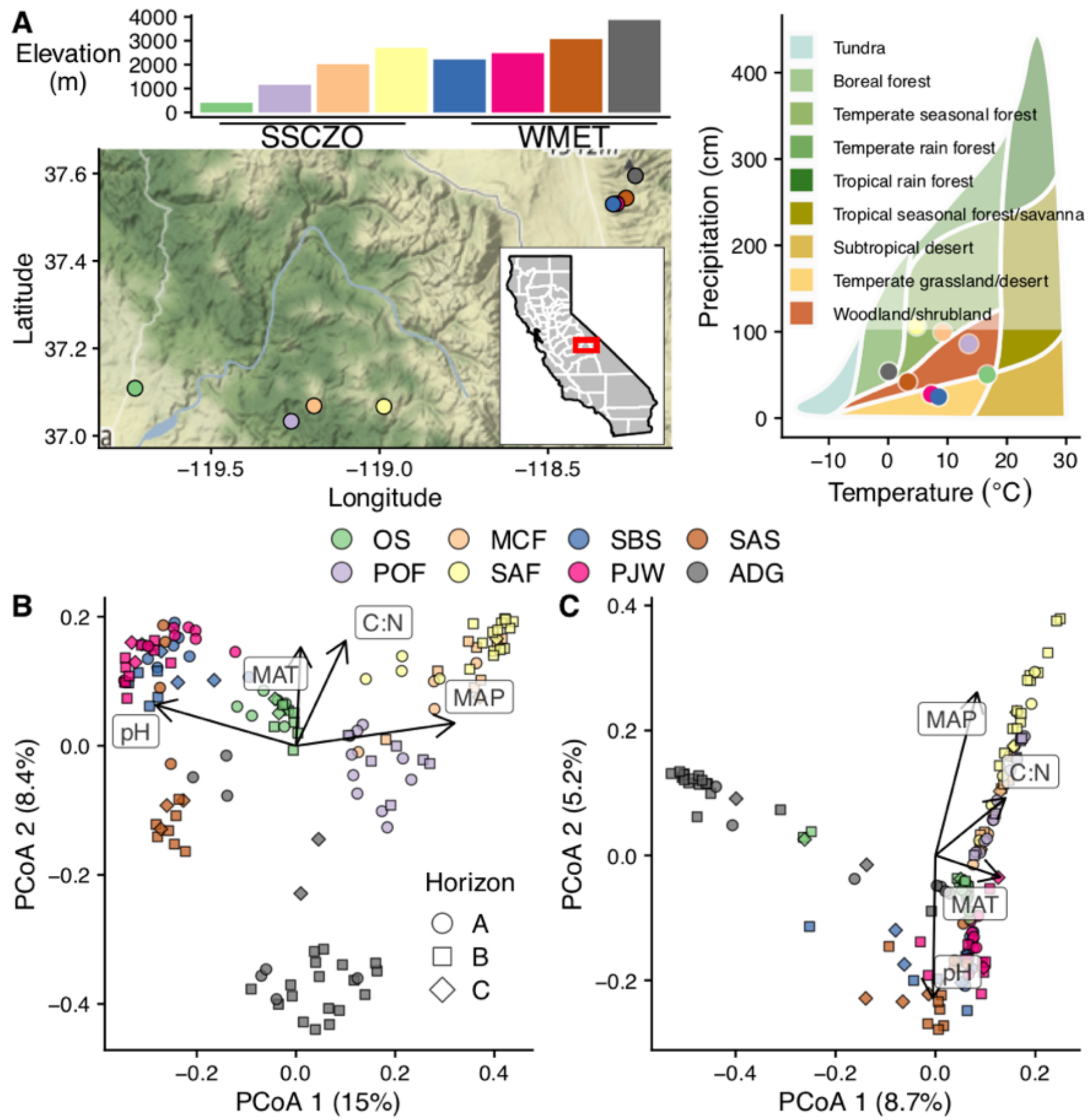

$\begin{array}{lll}\bigcirc & \text { SBS } & \text { SAS } \\ \text { PJW } \bigcirc & \text { ADG }\end{array}$

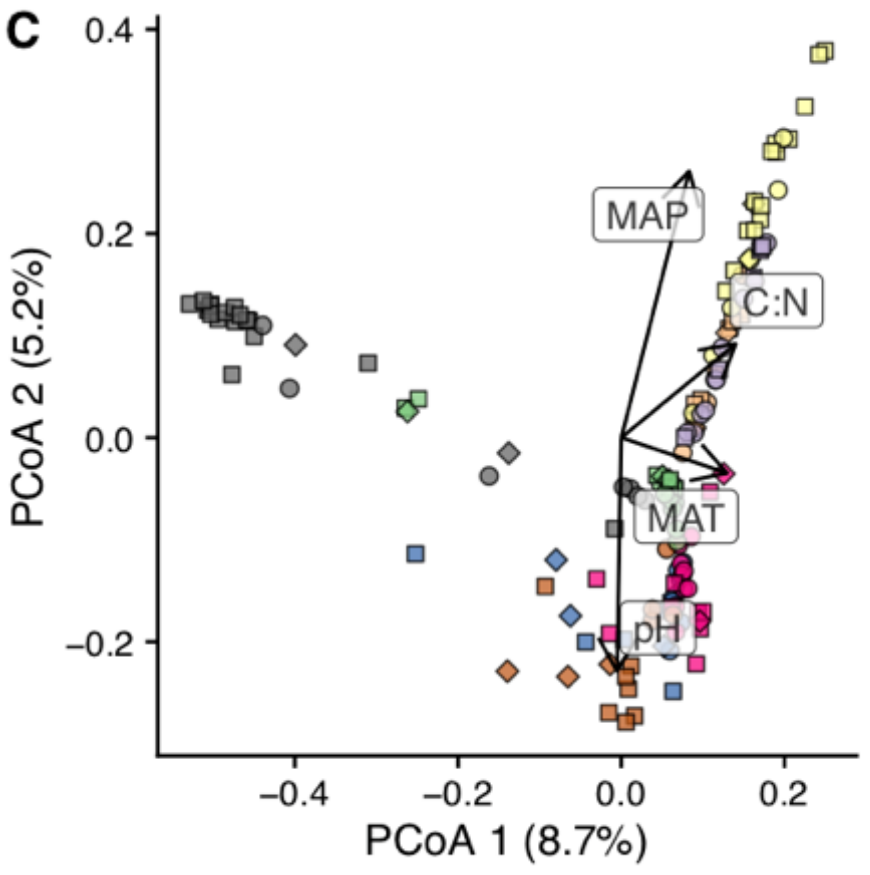

Figure 1

Overview of study sites (A), including elevation, location, and biome (note: while ADG is classified as a boreal forest, it is an alpine tundra). Principal coordinates analysis (PCoA) plots of prokaryote (B) and fungal (C) community composition. The percentage in parentheses indicates the variation explained by each axis. Vectors represent the direction and magnitude (indicated by vector length) of correlations of environmental variables 
with the first two axes of the PCoA. Key: MAP = mean annual precipitation, MAT = mean annual temperature, $\mathrm{C}: \mathrm{N}=$ the soil carbon-to-nitrogen ratio (molar basis).

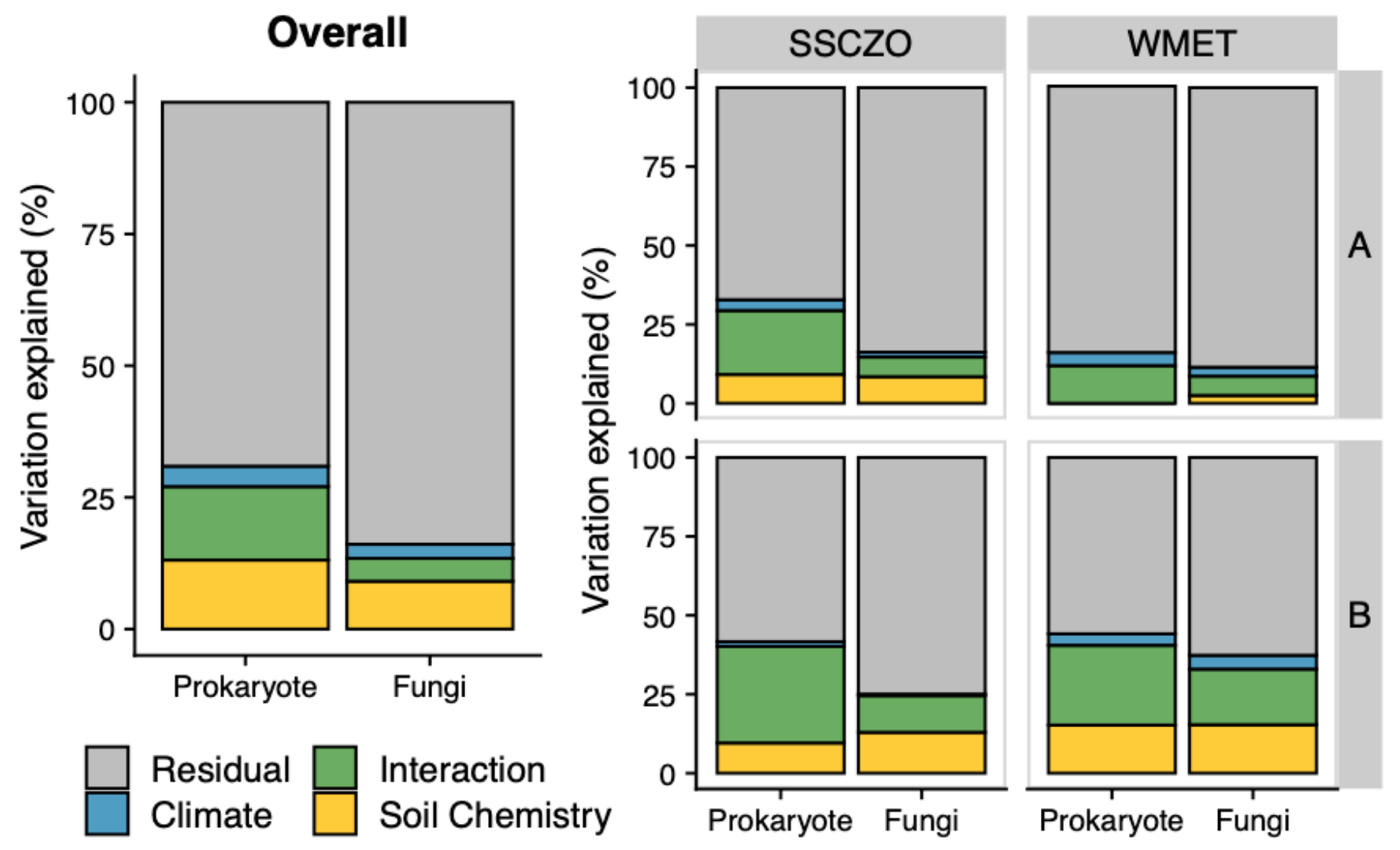

Figure 2

Variance partitioning from the PERMANOVA of prokaryote and fungal community composition, overall, across elevational gradients, and among major horizons (lack of samples in the $\mathrm{C}$ horizon prevented analysis in this layer). Climate is the combined effect of mean annual temperature and precipitation. Soil chemistry is the combined effect of $\mathrm{pH}(1: 2 \mathrm{CaCl} 2)$ as well as the concentration of total extractable aluminum, calcium, carbon, iron, magnesium, nitrogen, phosphorus, potassium, silicon, and sodium (mmol kg-1). 

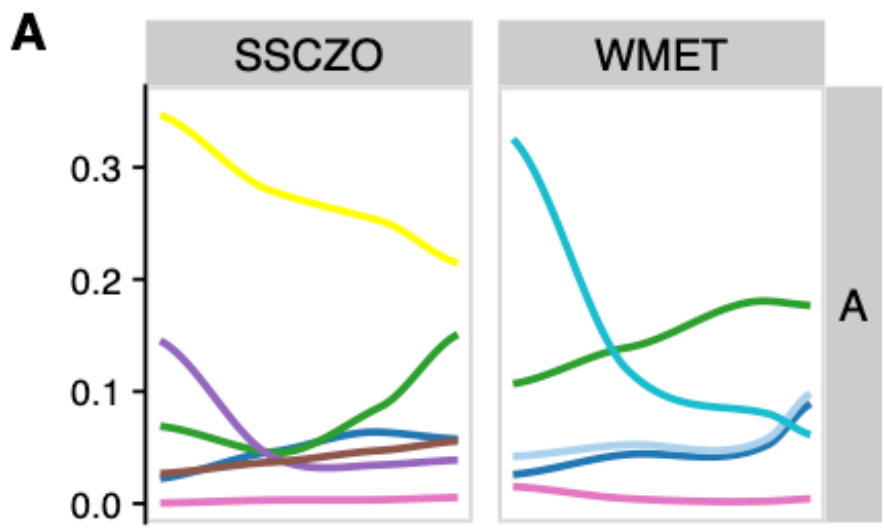

B
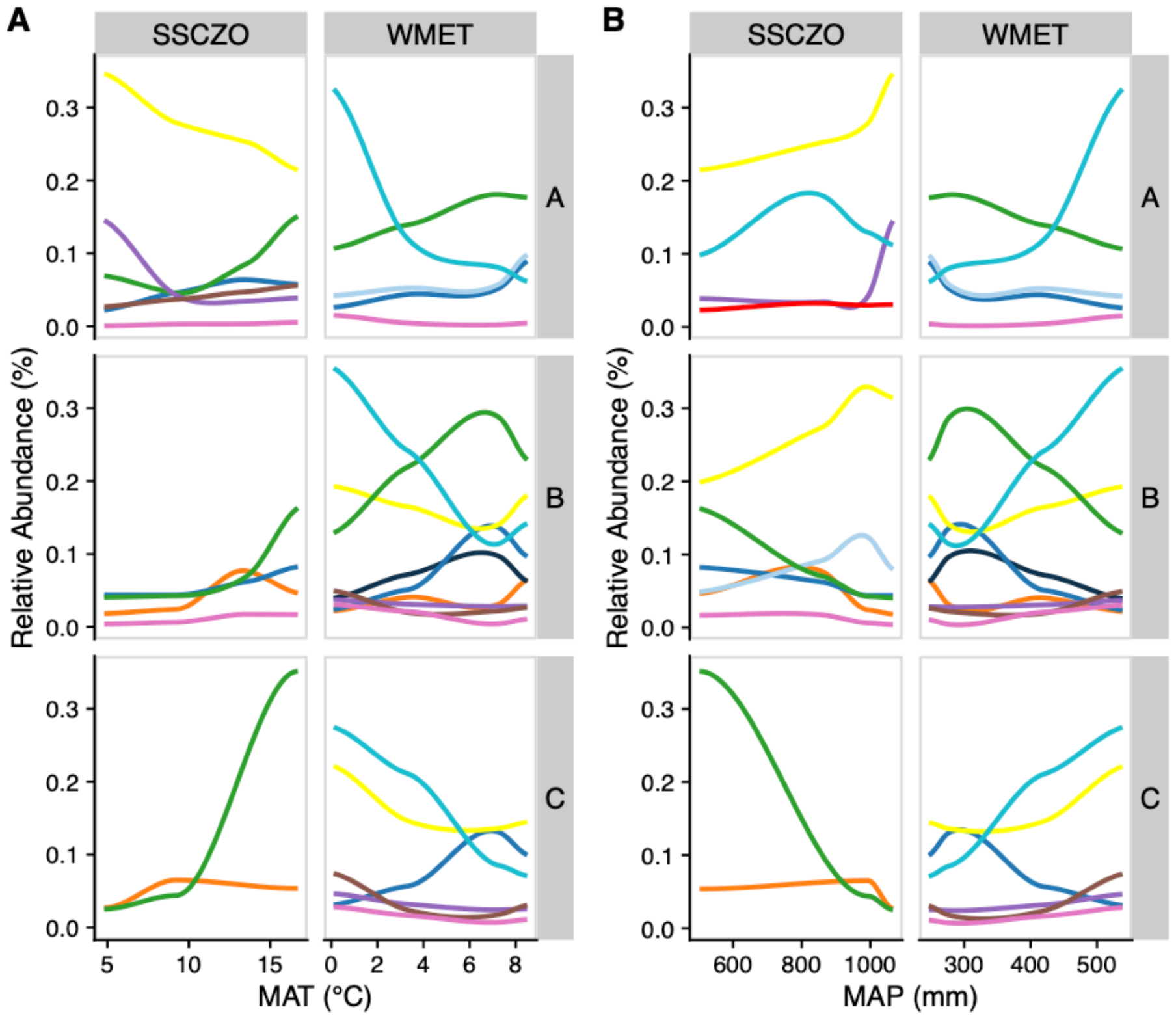

- Archaea

Acidobacteria

- Nitrospirae

- Alphaproteobacteria

Actinobacteria

- Planctomycetes

- Deltaproteobacteria

- Chloroflexi

- Verrucomicrobia

- Gammaproteobacteria - Gemmatimonadetes

\section{Figure 3}

Average relative abundance of prokaryotic taxa that significantly change ( $p$-adjusted $<0.05$ ) with mean annual air temperature (MAT, A) and mean annual precipitation (MAP, B) within each horizon and elevational gradient. Lines are calculated using loess regression. 
A
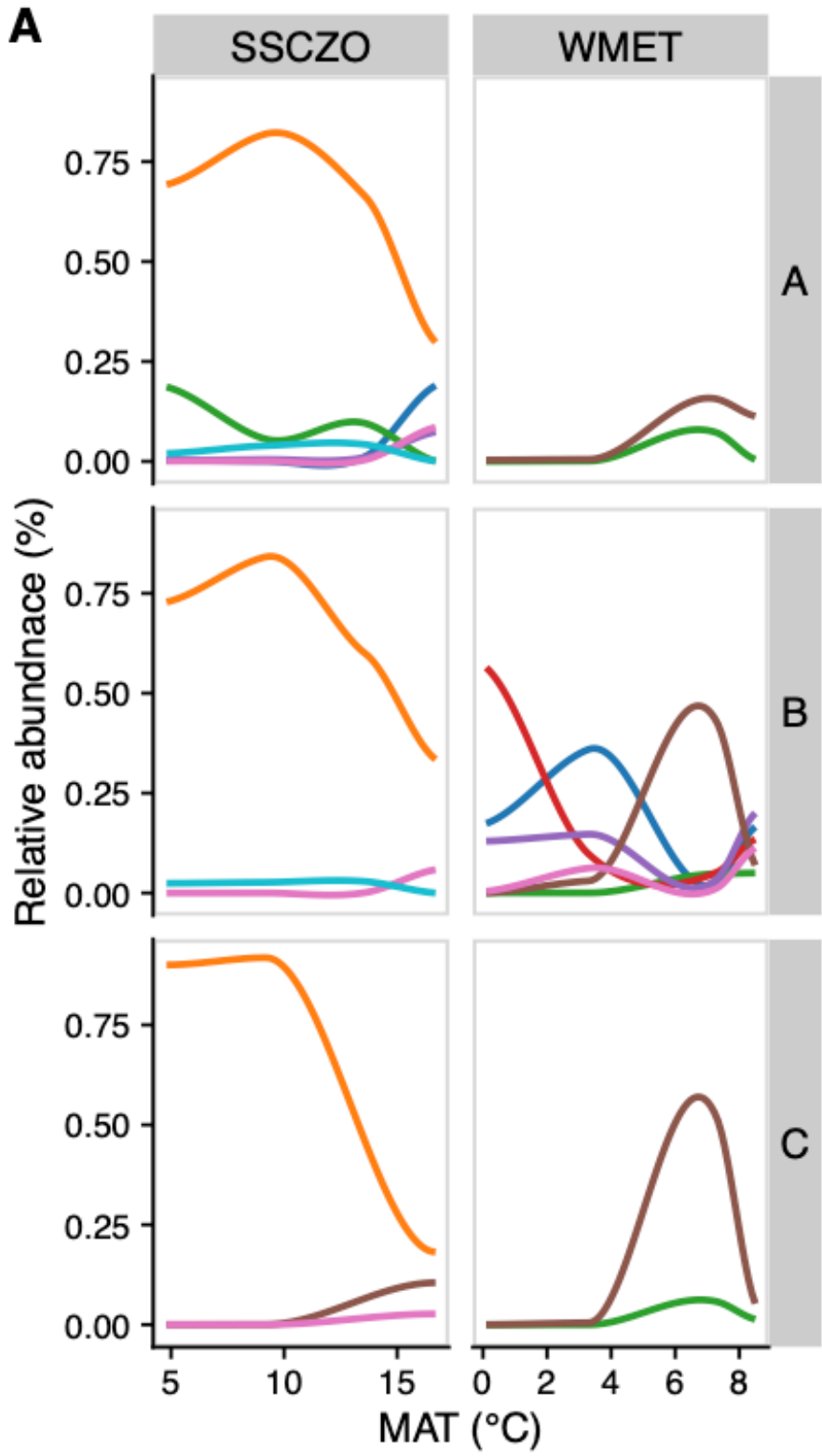

A

B
B
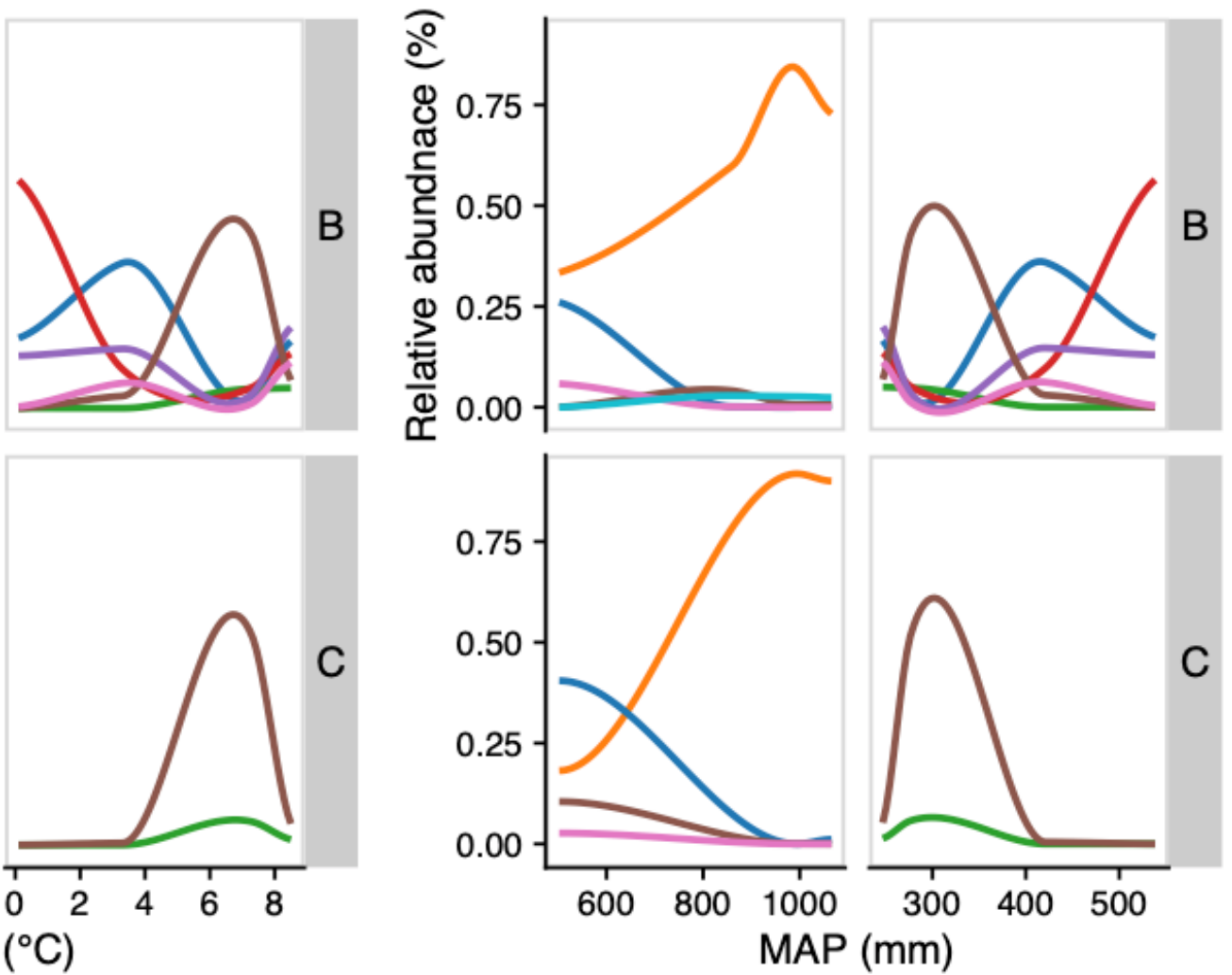

\section{- Agaricomycetes - Leotiomycetes - Sordariomycetes \\ - Dothideomycetes - Mortierellomycetes - Umbelopsidomycetes \\ - Geminibasidiomycetes - Pezizomycetes}

Figure 4

Average relative abundance of fungal classes that significantly change ( $p$-adjusted $<0.05$ ) with mean annual temperature (MAT, A) and mean annual precipitation (MAP, B) within each horizon and elevational gradient. Lines are calculated using loess regression.

\section{Supplementary Files}

This is a list of supplementary files associated with this preprint. Click to download. 